\title{
Current Situation, Obstacles and Solutions to China's Cross-Border E-Commerce
}

\author{
Yuye Fang \\ Beijing Institute of Fashion Technology, Beijing, China \\ Email: 583756007@qq.com
}

How to cite this paper: Fang, Y.Y. (2017) Current Situation, Obstacles and Solutions to China's Cross-Border E-Commerce. Open Journal of Social Sciences, 5, 343-351. https://doi.org/10.4236/jss.2017.510028

Received: September 28, 2017 Accepted: November 18, 2017 Published: November 21, 2017

\begin{abstract}
With the rapid development of global e-commerce and push of the government, cross-border e-commerce has developed into a new form of import and export trade, especially due to its advantage of breaking the time and space limitations of international transactions. This paper introduces the current situation of China's cross-border e-commerce, making comparison among cross-border e-commerce platforms and different business models, discusses the main obstacles facing China's e-commerce development, and projects the future trend. The paper explores possible solutions to problems such as poor customs clearance service, imperfect supervision system, and settlement difficulties, with a focus on improving China's e-commerce development.
\end{abstract}

\section{Keywords}

Cross-Border Electronic Supplier, Policies, Platforms, Models

\section{Current Situation of Cross-Border Electronic Commerce}

\subsection{Concept of Cross-Border Electronic Commerce}

Cross-border electronic commerce refers to import and export trade by means of different electronic commerce ways in different customs territory. The narrow concept of cross-border e-commerce refers to cross-border retail network, making deals on different e-commerce platform, by payment and delivery of goods through cross-border logistics. Cross border network retailing is a new form of trade generated by the development of Internet to a certain stage.

According to the type of interaction, the main modes of cross-border e-commerce can be divided into $\mathrm{B} 2 \mathrm{~B}, \mathrm{~B} 2 \mathrm{C}, \mathrm{C} 2 \mathrm{C}$ and so on, Among them, $\mathrm{B} 2 \mathrm{C}$ and $\mathrm{C} 2 \mathrm{C}$ are all facing the end consumer, so they can be collectively referred to cross-border network retail, 
Cross border e-commerce is also divided into platform type, self operation type and hybrid type (Figure 1).

\subsection{China's Cross-Border E-Commerce Growth}

In 2015, the total value of China's import and export of goods was 24 trillion and 590 billion yuan, decreased 7\% from 2014 [1]. Among them, exports of 14 trillion and 140 billion yuan, dropped 1.8\%; imports of 10 trillion and 450 billion yuan, also dropped $13.2 \%$. Judging from the current situation, China's foreign trade situation is still not optimistic in 2016, the pressure is still relatively large (Figure 2).

In 2015, despite the slowdown in Global trade, Chinese cross-border business growth has declined, but the growth rate of cross-border trade is still significantly higher than import and export trade business. China's permeability of cross border e-commerce in traditional trades is continuously improved [2].

2015, China cross-border electronic supplier transactions amounted to 4 trillion and 800 billion yuan, an increase of 28\%. Expected in 2020, cross-border electronic supplier market transactions will reach 12 trillion yuan, in the 2015-2020 years interval, compound annual growth rate of 20.1\% (Figure 3).

\begin{tabular}{ccc}
\hline Management model & Platform type & Self-operation type \\
\hline Cross-border B2B (export) & $\begin{array}{c}\text { Alibaba international station, } \\
\text { China manufacturing network, } \\
\text { Global resource network, } \\
\text { Dunhuang network }\end{array}$ & \\
Cross-border B2B (import) & 1688.com, seatent.com & \\
Cross-border & Quicksell, & \\
e-commerce retail (export) & Amazon, & Lanting Pavilion \\
& Wish & Gathering potential, \\
DX,
\end{tabular}

Figure 1. China's major cross-border electronic supplier management model classification.

\begin{tabular}{ccc}
\hline & Value of export (billion in dollar) & Year on year growth \\
\hline US & 410 & $3.5 \%$ \\
EU & 356 & $-3.9 \%$ \\
ASEAN & 279 & $2.6 \%$ \\
Japan & 135 & $-9.2 \%$ \\
India & 58 & $7.4 \%$ \\
Russia & 34 & $-35.2 \%$ \\
Brazil & 27 & $-21.5 \%$ \\
\hline
\end{tabular}

Figure 2. 2015 China's exports to major economies. Source: Customs general administration. 


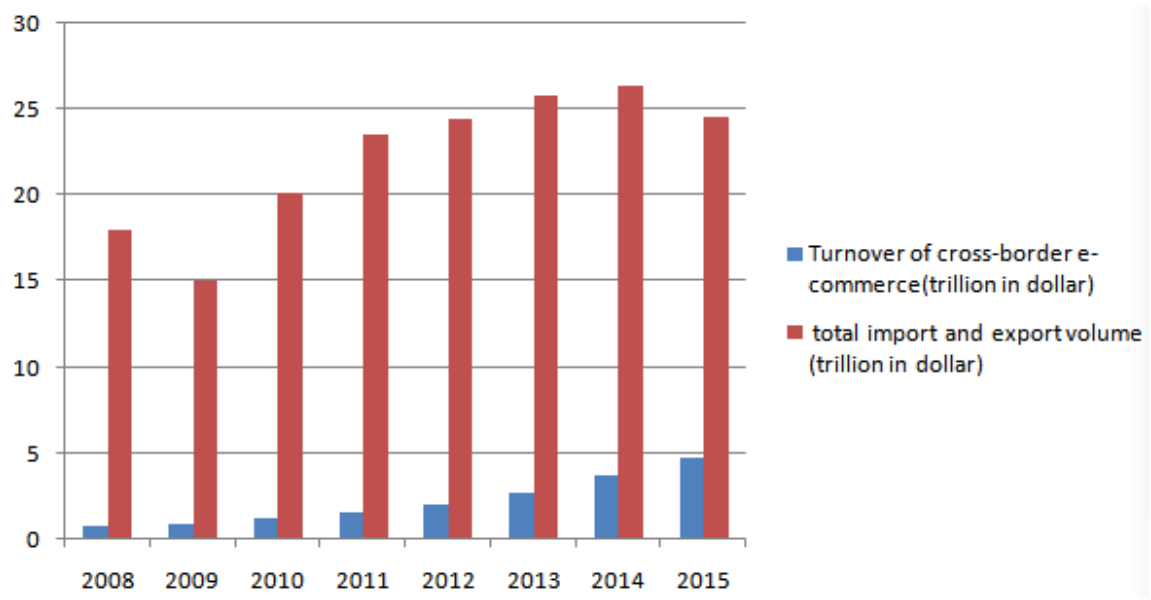

Figure 3. Turnover of China's cross-border e-commerce and total import and export volume change. Sources: Ministry of Commerce, General Administration of customs, Ai Rui, Analysys, Ali Research Institute.

In 2015, cross-border electronic transactions accounted for $19.5 \%$ of China's total imports and exports, which is expected by 2020 , the proportion will reach $37.6 \%$. China's cross-border electronic commerce is export-oriented [3]. In 2015, cross-border e-commerce exports accounted for $83.1 \%$ of total cross-border electronic transactions, imports accounted for $16.9 \%$. By 2020 , the proportion of cross-border electronic commerce import trading will rise to $25 \%$.

According to the business model, China cross-border electronic commerce is currently dominated by B2B in 2015, B2B accounted for $84.3 \%$ of the total amount of cross-border electronic providers, cross-border retail accounted for only $15.7 \%$, but the strong growth of cross-border retail electronic commerce, in 2020 is expected to account for more than $30 \%$.

\subsection{Four Growth Momentum of Cross-Border E-Commerce}

In recent years, the rapid growth of cross-border electronic commerce has accelerated consumption, trade, services and globalization of SEMs. China's cross-border electronic commerce development is particularly prominent, based on the following four reasons:

1) Growth momentum: technological progress

The popularization and development of the Internet, cloud computing and intelligent terminals are the basic conditions. In the traditional industrial era, multinational enterprises dominate international trade. It is difficult for consumers and small businesses to obtain sufficient market information, nor do they have the basic conditions for engaging in cross-border electronic commerce. Since the beginning of this century, the Internet technology and the rapid development of global business platform, the main market access to information rich and symmetrical, almost zero cost, and $\mathrm{C} 2 \mathrm{~B} / \mathrm{C} 2 \mathrm{M}$ consumer demand pulling large-scale production has gradually become reality. With the payment system improving, logistics aging and cost decreasing, cloud computing and big 
data are becoming more and more popular, and the professional services of cross-border trade are developing rapidly. These conditions laid a solid foundation for the rise of cross-border electronic supplier.

2) Consumption upgrade

The main driving force of China's economic growth will mainly come from consumption. In 2015, the contribution rate of consumption to China's national economic growth was further increased to $66.4 \%$, and the future will continue to rise. China is ushering in a new round of consumer spending. By 2020, China's middle class will be more than 200 million. The demand for overseas long tail, high-quality, low-cost and personalized products is becoming stronger and stronger.

Over the next five years, $42 \%$ of the incremental private consumption will be contributed by e-commerce. Online shopping is the base to create large-scale users of new consumer, as of the end of June 2016, Chinese online shopping users reached 448 million, online shopping utilization rate reached $63 \%$.

3) Industry foundation

The small and medium-sized enterprise in china is about 500 million, creating about $60 \%$ of the total amount of foreign trade, small and medium-sized enterprises continue to join the cross-border e-commerce market as a "global seller", making the cross-border electronic exports to maintain rapid development.

China has the advantages of traditional manufacturing base and superior export products, as well as design for consumer goods manufacturing technology and manufacturing level especially in the clothing, shoes and hats, bags, 3C, digital home appliances and other consumer goods.

4) Credit protection

From the perspective of China's cross-border electronic commerce development process, the credit system and secured transactions, is not only crucial for the development of Taobao and other retail platforms, but also for cross-border electronic supplier B2B development.

Although China's cross-border electronic commerce B2B platform started earlier, but in the past because there is no credit guarantee system, the overall development was slow. Since 2015, the Chinese Ali international as a representative platform for cross-border electronic commerce B2B has gradually changed into the trading platform, and accumulated business and credit data supported it. To provide integrated services through foreign trade platform, information of customs, inspection, tax, foreign exchange and other services, cross-border electronic business platform can help enterprises to establish a global network of trade credit system, so as to better access to international buyers trust and form a virtuous cycle.

\section{Main Obstacles in China's Cross-Border Electronic Commerce Development}

Although China's cross-border e-commerce has developed rapidly, the deficien- 
cies also seriously restrict the healthy development of cross-border e-commerce. The main focus is on the following aspects:

\subsection{Poor Customs Clearance Service}

Cross border B2B trade usually adopts traditional customs declaration, and its cumbersome customs formalities make the cross-border e-commerce efficiency greatly reduced. At the same time, cross-border online retail has the characteristics of high variety and high frequency. It also relies heavily on air bags, mail and express mail. Relevant government departments, in order to regulate the management of overseas purchasing activities, provide that all overseas express enterprises use EMS [4]. Customs clearance parcels must be in accordance with the customs clearance of trade goods, which directly lead to the contradiction between the traditional trade customs clearance and the features of the modern cross-border network retailing. More part of the electronic supplier enterprises do not have the right to import and export business, and their retail trade activities without customs declaration, cannot be related to settlement, tax rebates and other operations. In addition to customs clearance, tax rebates, settlement and so on, the sale of return is also a major problem troubled cross-border electronic supplier. The characteristics of e-commerce determine the high rate of return, and in some countries such as Europe and the United States, some countries with higher retail service levels generally return the goods unconditionally.

Therefore, the rate of exchange of cross-border e-commerce has also been increasing. However, due to cross-border customs clearance and logistics, it is difficult to have a smooth channel to return back. Moreover, these repair and return of goods usually have been regarded as imported goods, having to pay additional import tariffs, which makes China's electronic supplier enterprises heavily burdensome.

\subsection{Imperfection in the Market Supervision System}

Compared to the rapid development of cross-border e-commerce, the construction of the relevant market supervision system is lagging behind, and even blank. Only "Internet information services management approach" and a few laws and regulations involved in cross-border e-commerce. The core transactions, taxation and consumer rights protection and other content are lack of necessary and reasonable standard specification. The market supervision system is too weak, giving false propaganda and fake and shoddy commodities an opportunity. Illegal transactions and even fraud have occurred. And the lack of intellectual property rights laws and regulations to restrict the environment, the violation of intellectual property rights behavior is not curbed, making the overseas consumer complaints rate is also increasing.

The relevant statistics of the e-commerce platform eBay show that Chinese sellers have an average of 5.8 complaints per 100 transactions in eBay completed multinational transactions, which is two times as much as the global average (2.5). Some foreign e-commerce platforms have to make some strict rules for 
Chinese sellers: higher commissions or more severe penalties to maintain the order of transactions. This seriously affects the collective image of China's foreign trade providers. Also this is not conducive to creating an international environment conducive to cross-border e-commerce trade activities.

\subsection{The Unreasonable Mode of Settlement}

When conducting cross-border e-commerce, the electronic supplier usually adopts the following types of settlement: First is to set up more than one personal account. Part of the foreign trade supplier's monthly turnover is up to hundreds of thousand dollars. In order to avoid restrictions on foreign exchange quota, they are likely to open a number of accounts in disguised form to raise the total amount of foreign exchange settlement. Second, deal with foreign exchange through underground foreign exchange intermediaries. We shall use the special foreign exchange policy, which is not limited to the amount of foreign exchange settlement, to settle foreign exchange in a few areas of our country. In view of the current foreign trade suppliers more and more non-standard and inconvenient places, the relevant management departments need to take timely measures to improve and improve.

\section{Solution Cross-Border Electronic Supplier}

The problems exposed by cross-border e-commerce have seriously affected the normal operation of cross-border e-commerce, and at the same time restricted the pace of its development. In view of the current problems, the relevant departments and the majority of electronic supplier enterprises have taken targeted measures, from which we can predict some of the future trends of cross-border e-commerce.

\subsection{The Related Service Support System Should Be Optimized}

1) Lead by the General Administration of Customs to, a mechanism was set up to identify the cross-border electronic supplier enterprises, so as to determine the authenticity of the transaction entity in a timely and effective manner. Secondly, put all e-commerce import and export of goods under the supervision network of goods. By reference to the regulation of personal items, we are likely to build and perfect new customs supervision mode on direct import and online shopping bonded. Thirdly, about checklist release and customs clearance, the electronic supplier enterprise summary declaration, no longer separated by the individual electronic supplier to declare independently. Online related transactions, logistics and payment records can be used as the basis for cross-border trade in e-commerce export certification.

2) Take measures to continuously optimize the bonded areas, customs clearance and other aspects closely related to cross-border logistics and distribution, improve management standards, promote trade facilitation, making domestic logistics courier enterprises to carry out international business. Attract large in- 
ternational express enterprises, and domestic e-commerce enterprises, logistics and distribution enterprises to have in-depth cooperation and improve domestic logistics level. According to the actual situation, we have formulated a scientific and perfect service quality standard for cross-border logistics and distribution enterprises to ensure the quality of service of cross-border logistics enterprises.

Through the above measures, the development of cross-border e-commerce activities to support the service system will be improved, the protection effect of cross-border e-commerce development will become increasingly evident.

\subsection{Cross-Border E-Commerce Market Supervision System Should Be More Perfect}

Announcement of the General Administration of Customs (No. 56) "On the supervision of cross-border trade in e-commerce, inbound and outbound goods and articles." Announcement said that e-commerce enterprises or individuals which are get Customs approved and online transactions with the customs e-commerce platform, should accept customs supervision if they achieve cross-border transactions inbound and outbound. In addition, the operators who store the goods and articles of entry and exit of electronic commerce shall handle the filing procedures of the e-commerce business and accept the supervision by the customs.

E-commerce business or personal, payment companies, customs supervision operators, logistics enterprises, should send data on electronic commerce transaction, payment, data warehousing and logistics to the management platform in accordance with the provisions of the customs clearance services through e-commerce platform timely. This regulation means that the relevant government departments have begun to develop cross-border e-commerce market regulation research, take measures to build inter departmental daily cooperation mechanism, promote the construction of e-commerce supervision information system, gradually establish a credit system of cross-border e-commerce, to strengthen the norms and supervision of cross-border business platform and business enterprise business activities to crackdown on counterfeiting and infringement of intellectual property rights. Besides, the mechanism of cross-bor- der trade, e-commerce, mail, express inspection and quarantine supervision system has been established, to increase cross-border e-commerce product quality safety supervision. For overseas purchasing activities, the organization has formulated appropriate laws, norms, processes and channels. By taking these comprehensive measures, the current almost blank cross-border electronic supplier market supervision system will soon be established, and play its due role in supervision.

\subsection{International Cooperation in Cross-Border E-Commerce Has to Been Continuously Strengthened}

Because China's cross-border e-commerce has a huge customer base overseas, and the business in cross-border transaction process is often encountered the loss of the goods and customs clearance time and other problems, in the past 
China and relevant countries lack business exchanges and cooperation in this regard, so the problem has not been solved effectively [5]. For this short board, the Ministry of Commerce attaches great importance to start with the relevant countries actively consultations, and vigorously promote the research and development of cross-border e-commerce rules and treaties, gradually construct the bilateral and multilateral international cooperation in cross-border e-commerce system, creating conditions for activities of domestic business enterprise cross-border e-commerce. In the relevant bilateral and multilateral FTA negotiations, the Chinese government actively considers the problem of cross-border e-commerce development in China, they also male the rational use of the relevant international organization rules, effectively help to create the domestic enterprises to cope with cross-border e-commerce trade activities in dispute. As a kind of cross-border business activities, cross-border e-commerce cannot be separated from the governments of all countries, which will be developed and improved with the increasingly deep cooperation between China and other countries.

\subsection{Cross-Border Business Platform Will Have Greater Development}

Cross-border electronic business platform plays an important role. Compared with developed countries, China's cross-border business platform is still not developed enough. The relevant government departments have a clear understanding about that and gradually introduced specific support policies to secure the relevant platforms to carry out cross-border e-commerce effectively, in order to play their role in the integration of domestic enterprise resources, docking and other aspects of international market [6]. At the same time, actively support the cross-border electronic business platform to learn from the foreign advanced business platform and international standards as soon as possible, and then carry out the standardized management, improve service quality, summed up the domestic electronic trading mode. Through the encouragement and promotion of this series of policies, pace of development of cross-border electronic business platform in the future will be greater, while the overall level will have a relatively large upgrade.

\section{Conclusions}

E-commerce, as the product of information technology and commercial trade in the information age, has gradually taken the place of the traditional mode of trade. With the deepening development of China's reform and opening up and the integration with the world, cross-border e-commerce has gradually become an important branch of e-commerce. It plays an irreplaceable role in promoting the import and export of our country and satisfying the needs of people's daily life. While the pace of development of cross-border e-commerce in China is very fast, the scale is also growing, but we also cannot ignore the problems existing in the development of the regulatory system, settlement restriction factors, they all need for a national policy of continuous improvement to play a strong support- 
ing role. At the same time, for the enterprise, the problem of warehouse management standardization and intellectualization, transportation and distribution efficiency and strong cooperation, and procurement and supply chain management of big data need to be solved. For some time to come, to solve the key issues of logistics, warehousing and logistics big data, is very important for winning the cross-border electronic supplier market victory. And this requires enterprises to explore and perfect themselves.

To sum up, in order to seek better and faster development of China's cross-border e-commerce, the need for the help of relevant departments of the policy and the electronic supplier enterprise itself is important. Only when the relevant laws and regulations, construction, industry norms, enterprise back-end logistics procedures standardization, intelligence put into effect, the assistant guaranteeing effect of cross-border e-commerce development can be seen.

\section{Acknowledgements}

In the course of writing this thesis, my professor Yang, has given me meticulous guidance from the topic selection, framework of the thesis to details of the changes, and put forward a lot of valuable advice on that. Her realistic attitude towards learning, a high degree of professionalism, a conscientious and conscientious work style has an important influence on me. The thesis was completed under the careful guidance and support of Miss Leng.

At the same time, I would like to thank all the teachers who have given me the great motivation and confidence to complete this paper. After Thanksgiving, I sincerely ask all teachers to give more approval to my thesis.

Finally, I would like to express my heartfelt thanks to all the teachers who have reviewed this article.

\section{References}

[1] Dong, P. (2014) Analysis on the Future of Domestic Cross-Border E-Commerce. China Storage \& Transport Magazine.

[2] IResearch (2016) China Cross-Border Electronic Supplier Market Research Report.

[3] Liao Z. and Wang, M.Y. (2016) Analysis and Trend of Current Situation of Cross-Border E-Commerce. E-Business Journal.

[4] The Main Challenges and Policy Recommendations for Cross Border Electronic Business in China (2016) http://www.chinawuliu.com.cn/xsyj/201610/19/316227.shtml

[5] Zhen, L. and Wang, M.Y. (2014) Cross Boundary Electronic Supplier Present Situation Analysis and Tendency Discussion. E-Business Journal O2, 2014.

[6] Huang, Y.W. (2014) A Study on the Use of Cross Border E-Commerce in China's Small and Medium Enterprises. Journal of Dongbei University of Finance and Economics. 